\title{
DEGRADACIONA EFIKASNOST HETEROGENOG FENTON PROCESA U TRETMANU MAGENTA FLEKSO GRAFIČKE BOJE
}

\section{DEGRADATION EFFICIENCY OF HETEROGENEOUS FENTON PROCESS IN THE TREATMENT OF MAGENTA FLEXO PRINTING DYE}

\author{
Maja Kurdulija, Vesna Kecić, Miljana Prica, Fakultet tehničkih nauka, Novi Sad
}

\begin{abstract}
Oblast - GRAFIČKO INŽENJERSTVO I DIZAJN
Kratak sadržaj - Predmet istraživanja ovog master rada zahvata područje iz oblasti flekso štampe u cilju tretmana magenta flekso grafičke boje primenom Fenton procesa, kao $i$ ispitivanje uticaja pojedinih parametara na efikasnost obezbojavanja. Fenton proces je vrlo efikasan u degradaciji različitih vrsta boja. Zasniva se na dodatku Fentonovog reagensa, koji je mešavina vodonik-peroksida $i$ jona gvožđa $i$ bazira se na generisanju hidroksil radikala. Kao katalizator Fenton procesa korišćene su čestice nano nula valentnog gvožđa. "Zelena”sinteza nanomaterijala je sprovedena korišćenjem opalog lišća sa drveta hrasta koje raste u Nacionalnom parku Fruška Gora. Ispitivanje efikasnosti obezbojavanja vodenog rastvora grafičke boje vršeno je serijom eksperimenata na aparaturi za JAR test.
\end{abstract}

Ključne reči: flekso štampa, magenta, Fenton proces, nano nula valentno gvožđe, definitive screening design

\begin{abstract}
The aim of the master thesis is based on the flexographic printing field with the purpose to investigate the efficiency of Fenton process for treatment of Magenta flexographic dye, as well as to investigate the impact of various process conditions. Fenton process is very efficient in the degradation of various kinds of dyes. It is based on the addition of Fenton reagent, a mixture of hydrogen peroxide and iron ions, with the generation of hydroxyl radicals. Particles of nano-zero valent iron were used were used as a catalyst in Fenton process. The "green" synthesis of nanomaterial was carried out using fallen leaves of oak tree that grew in Fruška Gora National Park. Decolorization efficiency of printing dye aqueous solution was performed by series of experiments on the JAR test apparatus.
\end{abstract}

Keywords: flexographic printing, Magenta, Fenton process, nano-zero valent iron, definitive screening design

\section{UVOD}

Rešenju problema ispuštanja odpadnih voda, zaštite vodotokova i podzemnih voda u Srbiji se, na žalost, ne posvećuje adekvatna pažnja, ali rešenje postoji. Obojene otpadne vode u štamparijama nastaju nakon pranja valjaka štamparske mašine i posuda za čuvanje boje, pri

\section{NAPOMENA:}

Ovaj rad proistekao je iz master rada čiji mentor je bila dr Miljana Prica, vanr. prof. čemu se nakon završenog procesa štampe ispuštaju u recipijent $\mathrm{i}$ na taj način zagađuju životnu sredinu $u$ određenoj meri.

Fenton proces predstavlja jedan od najefikasnijih unapredjenih procesa oksidacije koji se primenjuje za oksidaciju/koagulaciju voda koje imaju visok sadržaj površinskih aktivnih materija, kao i mnogih drugih teško degradabilnih jedinjenja. Sam proces se bazira na generisanju hidroksil radikala u reakciji između jona gvožđa i vodonik peroksida [1]. Efikasnost oksidacionog Fenton procesa zavisi od faktora kao što su temperatura, $\mathrm{pH}$, koncentacija vodonik-peroksida i katalizatora i od redukcije $\mathrm{Fe}^{3+}$ do $\mathrm{Fe}^{2+}$. Stoga je od suštinske važnosti prisustvo reakcionih intermedijera sposobnih da redukuju $\mathrm{Fe}^{3+} \mathrm{i}$ regenerišu katalizator [2]. U nekim slučajevima zabeleženo je da povećanje koncentracije vodonikperoksida nema proporcionalni efekat na degradaciju substrata ili rastvorenog organskog ugljenika [3]. Međutim, smatra se da bi veća koncentracija $\mathrm{H}_{2} \mathrm{O}_{2}$ prouzrokovala njegovu nepoželjnu dekompoziciju na hidroperoksil radikale $(\bullet \mathrm{OOH})$ koji su znatno manje reaktivni od hidroksil radikala.

Jedna od prednosti Fenton procesa $u$ odnosu na druge oksidacione tehnike je to što nije neophodna upotreba energije za aktiviranje vodonik-peroksida, zato što se reakcija odvija na atmosferskom pritisku i na sobnoj temperaturi. Veliku primenu katalizatora u Fenton procesu imaju i nanomaterijali, tj. čestice nano nula valentnog gvožđa (eng. nano zero valent iron - nZVI). Male veličine čestica i velike površine medijuma čine nanočesticu gvožđa visoko reaktivnom i veoma nepostojanom. U poslednje vreme sve se više primenjuje Fenton proces gde se degradacija boja vrši pomoću čestica nano nula valentnog gvožđa, jer su one jeftinije i bezbedne po životnu sredinu. Velika pažnja je usmerena ka sintezi nZVI iz prirodnih proizvoda, kao što je lišće biljaka, koji imaju veliki antioksidativni kapacitet [4].

Eksperiment je vršen u cilju ispitivanja mogućnosti obezbojavanja sintetičkog rastvora obojenog magenta flekso grafičkom bojom primenom heterogenog Fenton procesa, gde je kao izvor gvožđa korišćeno nano nula valentno gvožđe sintetisano iz ekstrakta lišća hrasta.

\section{MATERIJALI I HEMIKALIJE}

Uzorak otpadne vode generisane nakon štampanja magenta bojom uzet je iz flekso štamparije koja se nalazi u Novom Sadu. Obojena otpadna voda nastaje nakon pranja valjaka štamparske mašine i posuda za čuvanje 
boje, pri čemu se nakon završenog procesa štampe ista ispušta $u$ recipijent $i$ na taj način zagađuje životnu sredinu.

$\mathrm{Za}$ pripremu radnih rastvora željenih koncentracija korišćena je dejonizovana voda. Odabrana flekso grafička boja (C.I.: PR57:1, CAS broj: 5281-4-9, hemijska formula: $\mathrm{C}_{18} \mathrm{H}_{12} \mathrm{~N}_{2} \mathrm{O}_{6}$, molarna masa: $352 \mathrm{~g} / \mathrm{mol}, \lambda \max$ : $573 \mathrm{~nm}$ ) spada u grupu azo boja i proizvedena je od strane Flint grupe. Strukturna formula magente je prikazana na slici 1 .<smiles>Cc1ccc(/N=N/c2c(O)c(C(=O)[OH2+])cc3ccccc23)c(S(=O)(=O)[O-])c1</smiles>

Slika 1. Strukturna formula magenta boje

\section{SINTEZA NANOMATERIJALA}

Priprema sakupljenog lišća za postupak ekstrakcije se odvijala u nekoliko faza. Prva faza podrazumevala je mlevenje lišća u kuhinjskom blenderu, koje je potom prosejano kroz sito dimenzija pora $2 \mathrm{~mm}$, nakon čega je materijal veličine manje od $2 \mathrm{~mm}$ sušen tokom 48 sati u sušnici na temperaturi od $50^{\circ} \mathrm{C}$. Ovako pripremljeno lišće je korišćeno dalje za ekstrakciju nano nula valentnog gvožđa prema proceduri Machado i sar [5].

\section{EKSPERIMENT}

\subsection{Efikasnost obezbojavanja}

Ispitivanje efikasnosti obezbojavanja vodenog rastvora grafičke boje vršeno je serijom eksperimenata na aparaturi za JAR test (FC6S Velp scientific, Italija). Sva spektrofotometrijska merenja, uključujući određivanje apsorpcionih maksimuma $\left(\lambda_{\max }\right)$ za ispitivanu boju kao i praćenje promene apsorbancije tokom eksperimenata, vršeno je korišćenjem UV-VIS spektrofotometra UV1800 PG Instruments Ltd T80+ UV/VIS, model: UV 1800 (Shimadzu, Japan). Merenje pH vredosti izvršeno je pomoću AD110 Adwa instrumenta. Efikasnost obezbojavanja izračunata je prema jednačini (1):

$$
\mathrm{E}(\%)=\mathrm{A}_{0}-\mathrm{A}_{\mathrm{t}} / \mathrm{A}_{0} * 100
$$

gde je: $A_{0}$ - početna apsorbancija obojenog vodenog rastvora boje ili efluenta; $A_{t}-$ apsorbancija vodenog rastvora uzorka nakon sprovedenog Fenton procesa.

\subsection{Definitive screening design}

Moćan alat za karakterizaciju sistema pod različitim eksperimentalnim uslovima podrazumeva integraciju jednostavnih i robusnih statističkih metoda $\mathrm{u}$ okviru primenjene metodologije, a sa ciljem dobijanja statistički značajnih zaključaka. U skladu s tim, nova generacija eksperimentalnog dizajna, definitive screening design (DSD) uvedena je 2011. godine od strane Jones i Nachtsheim [6]. U ovom radu DSD analiza je korišćena kako bi se ispitao uticaj četiri procesna parametra: početne koncentracije boje $(20-180 \mathrm{mg} / \mathrm{l})$, koncentracije gvožđa kao katalizatora u Fenton procesu $(0,75-60$ $\mathrm{mg} / \mathrm{l}), \mathrm{pH}$ vrednosti $(2-10)$ i koncentracije vodonik peroksida $(1-11 \mathrm{mM})$.

\section{REZULTATI I DISKUSIJA}

\subsection{Evaluacija modela}

U cilju karakterizacije sistema pod uticajem različitih procesnih uslova: koncentracije boje, koncentracije nZVI, $\mathrm{pH}$ vrednosti i koncentracije vodonik peroksida na efikasnost obezbojavnja vodenog rastvora magenta flekso grafičke boje sprovedeno je 14 eksperimenata, a rezultati su prikazani u tabeli 1 . Dobijeni rezultati ukazuju da je postignut širok opseg efikasnosti obezbojavanja od 8,78$92,79 \%$. Na ovaj način je potvrđena pretpostavka da sam proces uklanjanja boje u velikoj meri zavisi od primenjenih eksperimentalnih uslova, odnosno da pojedinačni parametri u određenoj meri doprinose efikasnosti Fenton procesa.

Tabela 1. Efikasnost obezbojavanja pri različitim eksperimentalnim uslovima

\begin{tabular}{|c|c|c|c|c|c|}
\hline Proba & $\begin{array}{c}\text { Koncentracija } \\
\text { boje [mg/l] }\end{array}$ & $\begin{array}{c}\text { Koncentracija } \\
\text { gvožđa [mg/l] }\end{array}$ & $\begin{array}{c}\text { Koncentracija } \\
\mathbf{H}_{\mathbf{2}} \mathbf{O}_{\mathbf{2}}[\mathbf{m M}]\end{array}$ & $\mathbf{p H}$ & $\begin{array}{c}\text { Efikasnost Fenton } \\
\text { procesa [\%] }\end{array}$ \\
\hline 1 & 20 & 0,75 & 11 & 6 & 9,35 \\
\hline 2 & 180 & 0,75 & 6 & 2 & 83,94 \\
\hline 3 & 20 & 30,375 & 11 & 2 & 92,79 \\
\hline 4 & 100 & 30,375 & 6 & 6 & 22,92 \\
\hline 5 & 100 & 0,75 & 1 & 2 & 15,23 \\
\hline 6 & 180 & 0,75 & 11 & 10 & 83,89 \\
\hline 7 & 20 & 60 & 6 & 10 & 55,53 \\
\hline 8 & 20 & 0,75 & 1 & 10 & 89,19 \\
\hline 9 & 100 & 60 & 11 & 10 & 45,73 \\
\hline 10 & 180 & 60 & 11 & 2 & 31,13 \\
\hline 11 & 180 & 30,375 & 1 & 10 & 90,07 \\
\hline 12 & 20 & 60 & 1 & 2 & 72,76 \\
\hline 13 & 180 & 60 & 1 & 6 & 17,24 \\
\hline 14 & 20 & 0,75 & 11 & 6 & 8,78 \\
\hline
\end{tabular}


Kako bi izveli regresioni model koji najbolje fituje dobijene rezultate, primenjena je regresiona analiza. Regresioni model obuhvata glavne faktore, njihove kvadratne vrednosti i dvofaktorske interakcije. Pored standardnih kriterijuma selekcije odgovarajućeg modela, dodatni tehnološki kriterijum bio je da modeli moraju da sadrže faktor koncentracije boje, ali i sve ostale ispitivane ulazne parametre, što je sa inženjerske tačke gledišta izuzetno bitno u ovom problemu. Sumarni prikaz modela prikazan je u tabelama 2 .

Tabela 2. Sumarni prikaz modela

\begin{tabular}{|c|c|}
\hline Deskriptivni faktor & Vrednost \\
\hline $\mathrm{R}^{2}$ & 0,984 \\
\hline $\mathrm{R}^{2}$ Adjusted & 0,942 \\
\hline RMSE & 5,612 \\
\hline
\end{tabular}

Iz sumarnog prikaza modela mogu se uočiti visoke vrednosti koeficijenta determinacije $\left(\mathrm{R}^{2}=0,984\right)$, prilagođenog koeficijenta determinacije $\left(\mathrm{R}^{2}\right.$ adjusted $=$ $0,942)$ i vrlo mala razlika između ova dva koeficijenta, što ukazuje na odsustvo prevelikog prilagođavanja modela podacima.

\subsection{Optimizacija Fenton procesa}

Optimizacija procesnih uslova izvršena je u okviru granica testiranih varijabli: $20 \leq \mathrm{x} 1 \leq 180,0.75 \leq \mathrm{x} 2 \leq 60$, $1 \leq \mathrm{x} 3 \leq 11,2 \leq \mathrm{x} 4 \leq 10$. Profil za predikciju sa optimalnim vrednostima je prikazan na slici 2 .

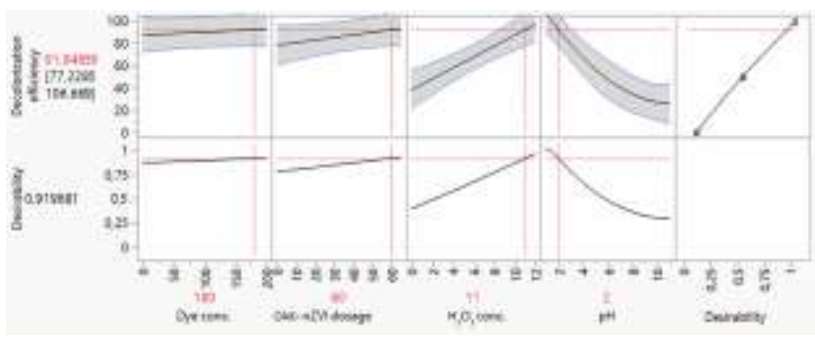

Slika 2. Optimalni uslovi Fenton procesa

$\mathrm{Na}$ osnovu dobijenih rezultata ustanovljeni su sledeći otpimalni uslovi: koncentracija boje $180 \mathrm{mg} / \mathrm{l}$, koncentracija nZVI $60 \mathrm{mg} / \mathrm{l}$, koncentracija vodonik peroksida $11 \mathrm{mM}$ i pH vrednost 2, pri čemu statistički model predlaže efikasnost procesa od 91,94\%. Dobijeni rezultati ukazuju na to da se efikasnost procesa dekolorizacije značajno povećava sa smanjenjem $\mathrm{pH}$ vrednosti i povećanjem koncentracije vodonik peroksida.

Sa dijagrama odzivne površine (slika 3a) zaključuje se da se maksimalna efikasnost dekolorizacije postiže prilikom povećanja doze nZVI od 0,75 do $60 \mathrm{mg} / \mathrm{l}$, dok se $\mathrm{H} 2 \mathrm{O} 2$ drži na visokom nivou (11 mM). Ovaj fenomen se može pripisati činjenici da je degradacija organskih zagađujućih materija tokom heterogenog Fenton procesa uzrokovana reakcijom organskih molekula sa $\bullet \mathrm{OH}$ radikalima nastalim degradacijom vodonik peroksida. Efikasnost Fenton procesa će se povećati sa većom koncentracijom katalizatora gvožđa, koja u ovom slučaju potiče od nZVI, ali i sa visokom koncentracijom $\mathrm{H}_{2} \mathrm{O}_{2}$, što dovodi do veće proizvodnje $\cdot \mathrm{OH}$ radikala $\mathrm{i}$ brže degradacije boje [7]. Uzimajući u obzir drugu značajnu interakciju (slika 3b), visok nivo koncentracije $\mathrm{H}_{2} \mathrm{O}_{2}$ pokazuje ne samo najistaknutiji efekat na uticaj $\mathrm{pH}$, već takođe omogućava optimalnu efikasnost uklanjanja boje. Ovaj zaključak je u saglasnosti sa prethodnim istraživanjima, koji takođe tvrde da je $\mathrm{pH}$ vrednost jedan od ključnih faktora koji utiču na efikasnost uklanjanja boje Fenton procesom. Za $\mathrm{pH}$ vrednosti veće od 5, efektivnost Fenton procesa je smanjena, što se može objasniti precipitacijom $\mathrm{Fe}^{3+} \mathrm{u}$ obliku hidroksida gvožđa. Zbog toga je favorizovana $\mathrm{pH}$ vrednost 2-3, što dovodi do optimalne brzine stvaranja slobodnih radikala.

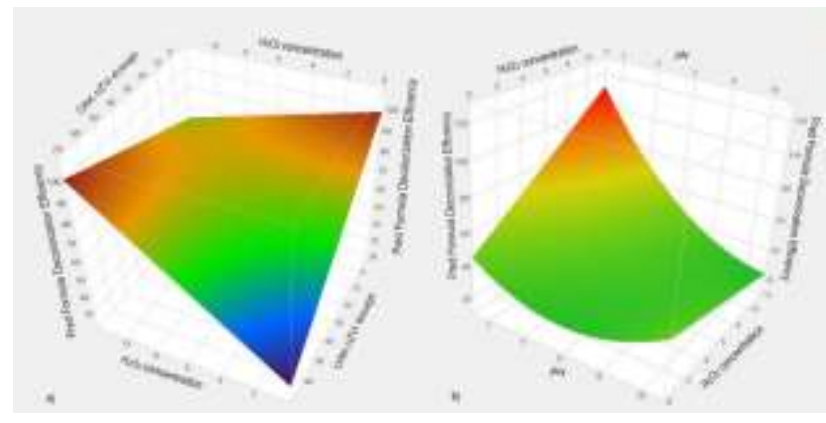

Slika 3. Dijagram odzivne površine statistički značajnih dvofaktorskih interakcija

\subsection{Tretman realnog efluenta}

Realan efluent generisan nakon procesa štampe, obojen magenta bojom je podvrgnut tretmanu primenom Fenton procesa pri optimalnim dozama ispitivanih parametara, $\mathrm{u}$ cilju utvrđivanja mogućnosti primene sintetisanog nanomaterijala. Efikasnost uklanjanja boje je praćena $\mathrm{u}$ vremenskom intervalu od 120 minuta, a rezultati su prikazani na slici 4. Degradaciona efikasnost nakon 60 . minuta je imala vrednost od $84,06 \%$. Neznatno povećanje maksimalne efikasnosti Fenton tretmana (do 86\%), postignuto je pri dužem reakcionom vremenu. U poređenju sa tretiranim sintetičkim rastvorom magenta boje, efikasnosti procesa u slučaju realnog efluenta su bile niže, što je posledica prisustva različitih organskih i neorganskih jedinjenja u kompleksnom matriksu efluenta. Pomenute organske i neorganske vrste mogu da imaju inhibitorni efekat na proces degradacije boje, ponašajući se kao hvatači hidroksil radikala i na taj način ostvaruju kompeticiju za aktivna mesta na površini katalizatora.

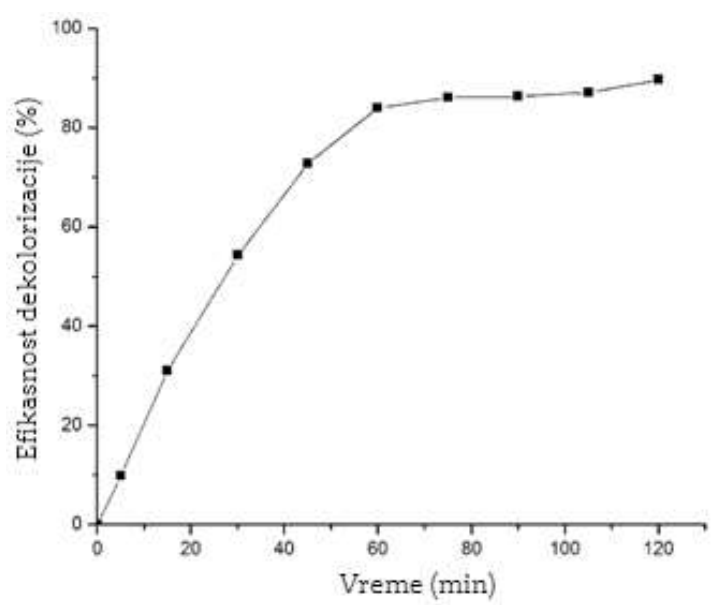

Slika 4. Zavisnost efikasnosti obezbojavanja od reakcionog vremena 


\section{ZAKLJUČAK}

Zagađenje voda predstavlja jedan od najaktuelnijih problema vezanih za život i opstanak čoveka. Visokom stepenu zagađenja čovekove okoline pored ostalog doprinosi i ispuštanje otpadnih industrijskih voda u rečne tokove, među kojima je od velikog značaja otpadna voda iz štamparske industrije.

Eksperimentalni deo rada vršen je u cilju degradacije magenta flekso grafičke boje pomoću čestica nano nula valentnog gvožđa i na osnovu četiri različita parametara (koncentracija boje 20 - $180 \mathrm{mg} / \mathrm{l}$, koncentracija nZVI $0,75-60 \mathrm{mg} / \mathrm{l}$, koncentracija vodonik peroksida $1-11$ $\mathrm{mM}$ i pH vrednost 2 - 10) kojima su simulirane koncentracije u različitom opsegu, došli smo do saznanja koji od njih najviše utiče na efikasnost obezbojavanja, a samim tim i na optimalne uslove.

Nakon dobijenih rezultata merenja, ustanovljeni su sledeći otpimalni uslovi: koncentracija boje $180 \mathrm{mg} / \mathrm{l}$, koncentracija nZVI $60 \mathrm{mg} / \mathrm{l}$, koncentracija vodonik peroksida $11 \mathrm{mM}$ i pH vrednost 2, pri čemu efikasnost obezbojavanja dostize vrednost do $91,94 \%$.

Dobijeni rezultati ukazuju na to da se efikasnost procesa dekolorizacije značajno povećava sa smanjenjem $\mathrm{pH}$ vrednosti i povećanjem koncentracije vodonik peroksida. Primenjeni Fenton proces je ostvario veliku efikasnost od $84 \%$ i u pogledu tretmana realnog enfluenta generisanog nakon procesa flekso štampe.

\section{LITERATURA}

[1] J.J. Pignatello, E. Oliveros, A. Mackay, "Advanced oxidation processes for organic contaminant destruction based on the Fenton reaction and related chemistry", Critical Reviews in Environmental Science and Technology, Vol. 36, pp. 1-84, Januar 2006.

[2] Y.M. Liu, J. Xu, L. He, Y. Cao, H. He, D.Y. Zjao, J.H. Zhuang, K.N. Fan, "Facile Synthesis of Fe-Loaded Mesoporous Silica by a Combined Detemplation Incorporation Process through Fenton's Chemistry", J. Phys. Chem., Vol. C112, pp. 16575-16583, Septembar 2008.

[3] H. Khalil, K. Tiangoua, M. Ghouti, "Synthesis of the mixed oxides of iron and quartz and their catalytic activities for the Fenton-like oxidation", Catal. Commun., Vol. 9(5), pp. 955-959, Mart 2008.
[4] D. Tomašević, "Primena stabilizovanog nano nula valentnog gvožđa $i$ komercijalnih imobilizacionih agenasa za remedijaciju sedimenta kontaminiranog metalima”, Doktorska disertacija, Prirodno-matematički fakultet, Univerzitet u Novom Sadu, Novi Sad, 2013.

[5] S. Machado, S. Pinto, J. Grosso, H. Nouws, J. Albergaria, C. Delerue-Matos, "Green production of zero-valent iron nanoparticles using tree leaf extracts", Sci. Total Environ., Vol. 445-446, pp.1-8, Februar 2015.

[6] M. Fidaledo, R. Lavecchia, E. Petrucci, A. Zuorro, "Application of a novel definitive screening design to decolorization of an azo dye on boron-doped diamond electrodes" Int. J. Environ. Sci. Te., Vol. 13, pp. 835-842, Januar 2016.

[7] V. Kecić, Đ. Kerkez, M. Prica, O. Lužanin, M. Bečelić-Tomin, D. Tomašević Pilipović, B. Dalmacija, "Optimization of azo printing dye removal with oak leaves-nZVI/ $\mathrm{H}_{2} \mathrm{O}_{2}$ system using statistically designed experiment", J. Clean. Product., Vol. 202, pp. 65-80, Novembar 2018.

\section{Kratka biografija:}

Maja Kurdulija je rođena u Smederevskoj Palanci 1993. godine. Diplomski rad na Fakultetu tehničkih nauka iz oblasti Grafičko inženjerstvo i dizajn odbranila je 2016. godine.

Vesna Kecić je od 2014. godine u zvanju asistenta na Departmanu za Grafičko inženjerstvo i dizajn.

Miljana Prica je od 2014. godine u zvanju vanrednog profesora na Departmanu za Grafičko inženjerstvo i dizajn. 